\title{
The Language of Rendering in Architectural Visualisations
}

\author{
Cristiana Bartolomei \\ Cecilia Mazzoli \\ Caterina Morganti
}

Abstract

The contribution proposes a methodology of multidisciplinary investigation on visualisation in architecture in order to understand and describe the origins and characteristics of images generated by graphic rendering tools. Renderings constitute a language of representation that plays a decisive role in the communication of design, because they are able to shape the imaginary and anticipate artistic and architectural trends. The literature in the field of architectural visualisation focuses almost exclusively on technological advances (software and hardware), neglecting many of the aspects that contribute to the image processing. After a recognition and classification of the types of renderings most commonly used in the artistic and architectural field, the main graphic and geometric connotations that underlie them are identified, in order to recognise the origins and the stylistic and historical-cultural influences that have contributed to their generation. Each rendering has its own precise style, in terms of graphics and content of the representation, aimed at attracting a specific audience to which it communicates certain information. Regardless of the aim to be achieved by the representation of a project through the use of renderings, the high potential of these representation tools for communication, media and social issues becomes apparent.

Keywords

digital art, rendering, architectural visualisation, graphic language, communication.

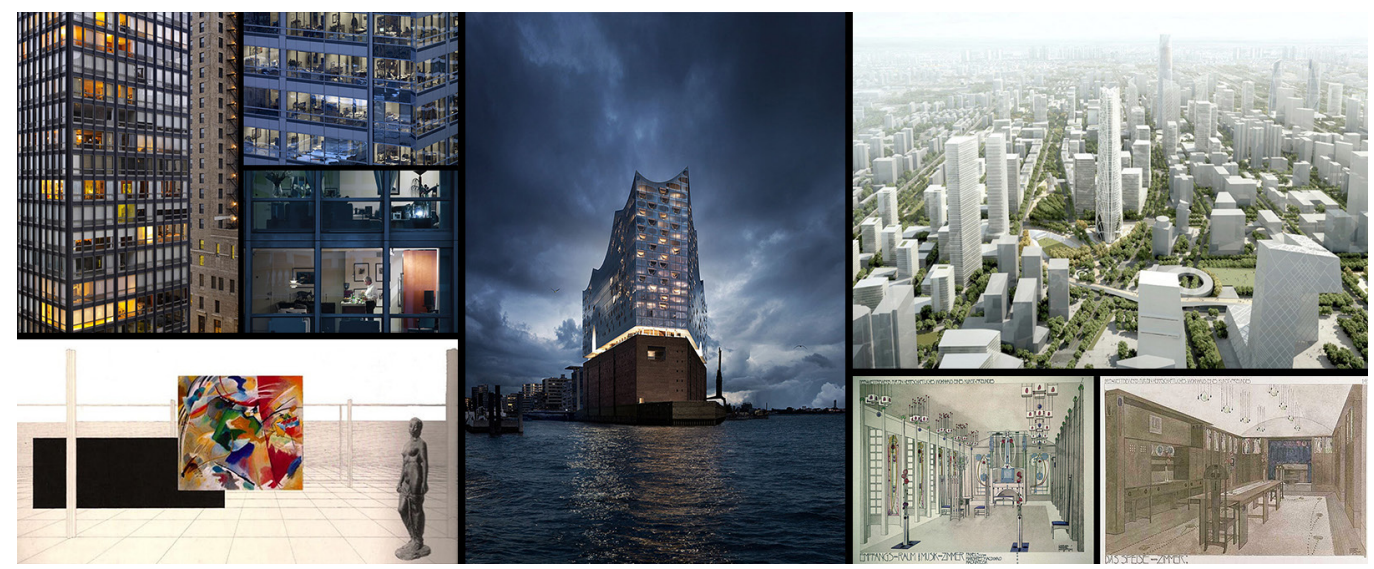




\section{Introduction}

The purpose of this research is to understand the language of visualisation of images generated by renderings in architecture, and to identify common aspects of representation in the various phases of communication of the design idea. Although renderings are nowadays considered indispensable in all sectors of architecture and they are also present in many other fields (e. g. cinema, videogames, advertising), a critical reflection on this subject in the literature is lacking. It is possible to define the language -intended in the broader sense of that used in direct communication- as the instrument that allows the transposition of an idea. In the field of representation, one of the most used languages is the so-called 'rendering', characterised by a certain aesthetic value attributed to images, ranging from abstract images to photorealistic renderings [Biehl-Missal 20I3, pp. 356, 367]. There is no doubt that today, often, design and representation have increasingly different authors: in particular, often the authors of the rendering are not the authors of the project. By rendering we mean the process that leads from the digital representation of a three-dimensional scene, defined in the modelling phase, to a two-dimensional projection of the view of the scene. And so, in order to achieve the objective set, that is understanding the language behind a rendering, we have to extend the field of investigation [Moon 2005]. It is not enough to look at the peculiarities of the field of representation, but its intersections with the history of art, the psychology of form, aesthetics and neuroaesthetics must be studied, and including very complex themes such as the relationship between representation and perception, the optics of vision, and the theory of colour [Husserl 1965]. The study is therefore based on multidisciplinary research from different sources, including photography, painting and cinema, but also on ideas taken from television series and video games. The language of rendering has a hybrid nature and is capable of radically changing the representation of a design project. In common practice, when we describe a project, we generally use its graphic documentation, neglecting those phenomena that influence our sensorial experience, which on the contrary strongly penetrate the language of rendering [Lukacher 2006]. The recent trend in rendering, that of photorealism which accompanies large-scale contemporary architectural projects, generates images which no longer resemble drawings or models, but increasingly photographs, able to show the non-professional users as if they had already been built [Pinotti 2014, pp. 269-296].

Renderings in the field of architecture can be defined as perspective representations of architecture and landscape, which have found their references in the works of painters, set designers and architects since the 1400s. For them the work and the images coincided, and perspective was used as a language of invention. During the 1800 s, the use of renderings in architecture was consolidated when British architects began to commission famous painters to paint the perspectives of their projects for exhibitions at the Royal Academy. Another decisive step occurred during the 1900s, when the relationship between architects and photographers became crucial; photorealistic rendering today seems to want to merge architecture and photography.

Rendering, in all its many forms as we will see below, is always aimed at prefiguring an idea with a strong persuasive power on society [Cusson, Cardoso 2007]. On the one hand, it is well established that it helps visualise the created project, it crystallises thoughts in the designer's mind and it succeeds in interpreting the meaning of the construction [Pepperell 20I I, pp. I-12]. On the other hand, it is certainly a powerful language aimed at influencing future architectural and urban planning choices, creating new building typologies and finally influencing social values on architecture [Rose et al. 20I4, pp. 386-403]. Its communicative nature, which has always been recognised, if once it was only used for an audience presentation -therefore at the end of the design process- today it is also used in the early stages of a project development and therefore gains the role of a real language in all phases of the design process [Robin 1997]. The way of designing, and consequently the representation of the project, changes and becomes "by images" through a repeated process of modelling and rendering [Elkins 1994, pp. 335-342]. The main element in the construction of a good rendering is still geometry, i. e. the definition of the geometry of each component of the 


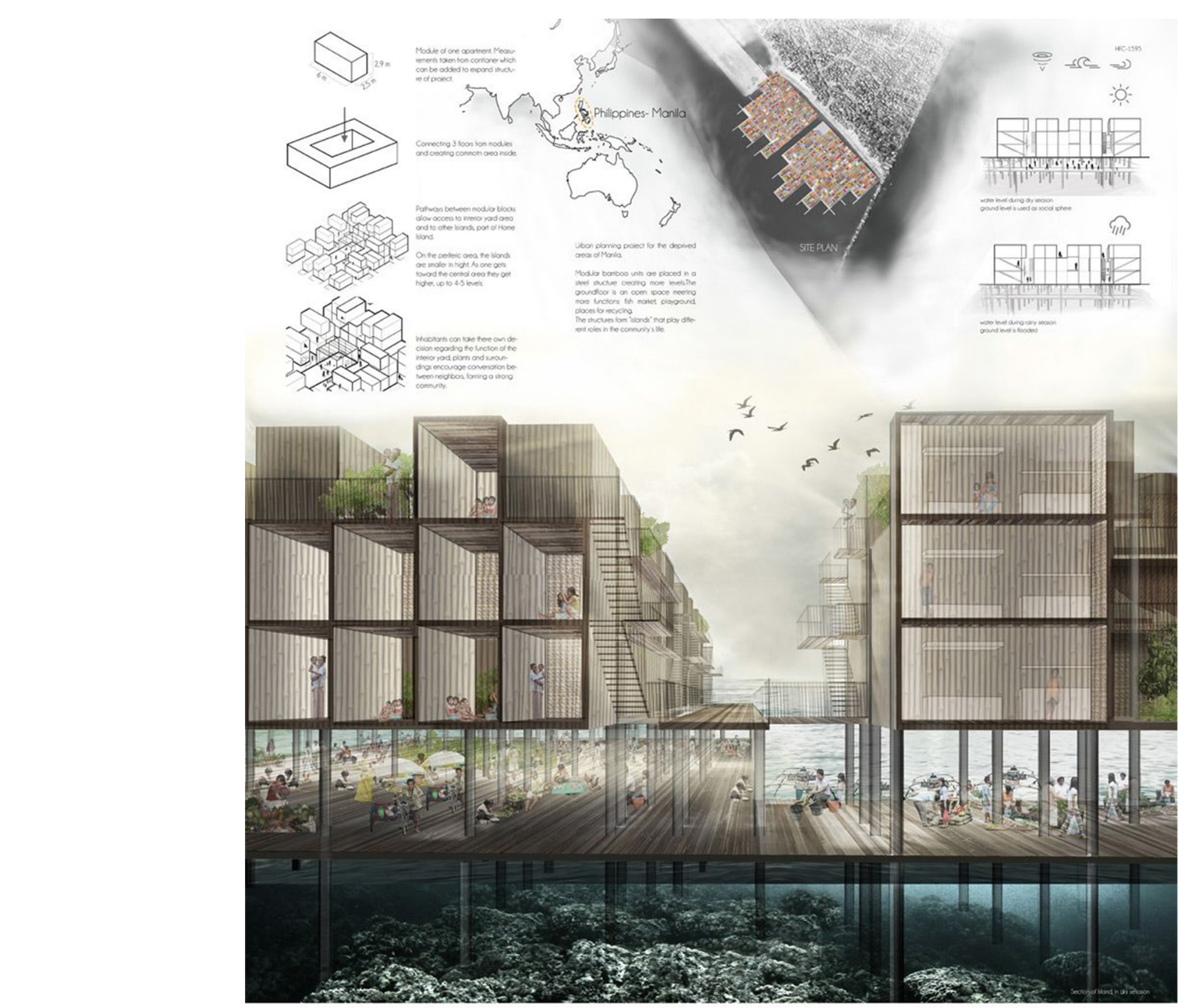

Fig. I. Example of conceptual rendering.
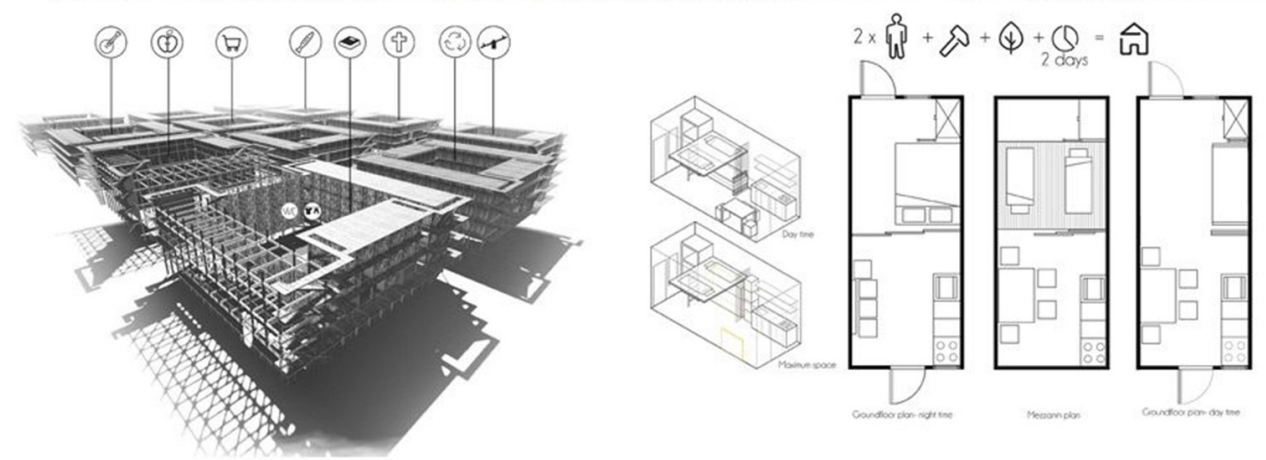
Fig. 2. L. Mies Van Der Rohe, project for a Museum for a SmallTown, perspective, $1941-1943$. three-dimensional view, to which, however, other elements are associated such as transformations (rotations, translations, and scale transformations), points of view, lights (directional, point, spot, area, volume, ambient, key, fill, back, kicker, special, and bounce light), light attributes (including shadowing, dropoff, direction), light properties (such as intensity, colour and effects) and finally material textures.

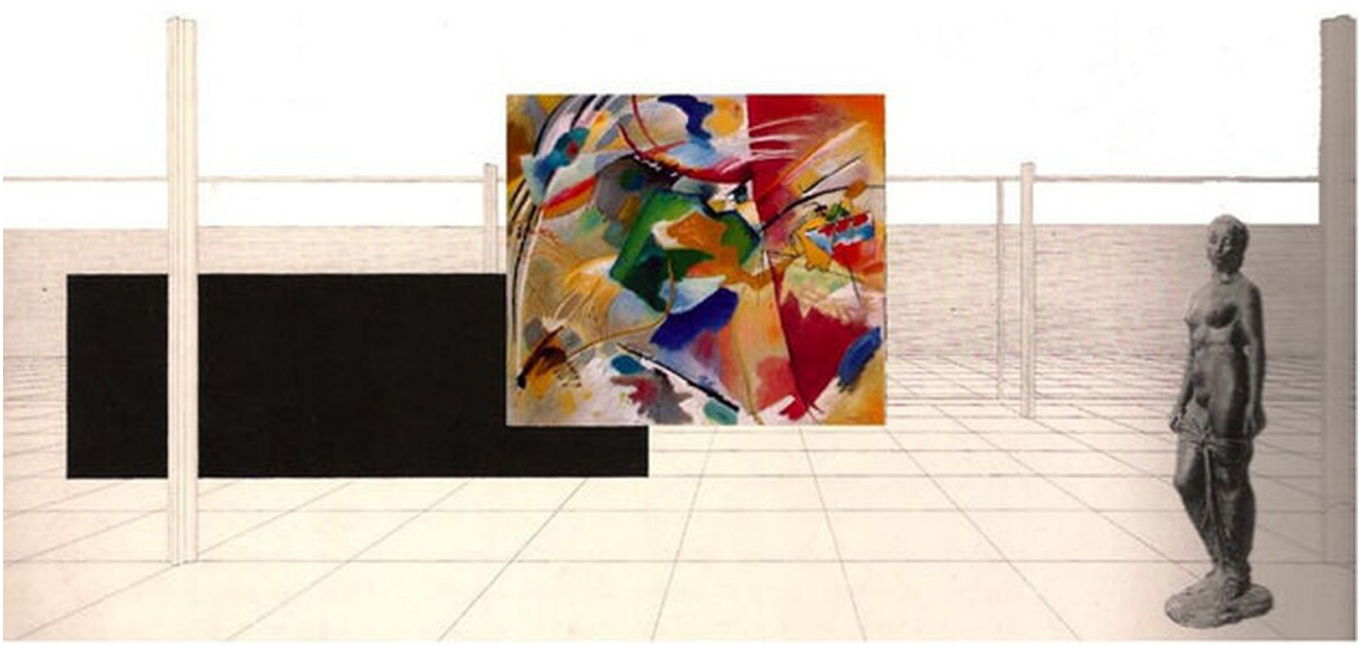

\section{Rendering variations}

Although renderings increasingly seek to achieve a high degree of visual realism, actually some renderings pursue verisimilitude rather than reproduction of the real. It is well known that renderings can be organised on an ascending scale, from the most abstract and symbolic to the most realistic, using images such as orthogonal projections of wire figures, perspectives of wire figures, removal of invisible lines and surfaces, local lighting patterns with their own shadows, shading flat polyhedra, shading smooth polyhedra, shadows, textures and surface effects, simulated reflections, global lighting patterns and photo realism. However, to investigate the language it is more interesting to classify them in another way. A first type of rendering is conceptual, which finds its origins in collage (fig. I) (a combination of photographs of the model, drawings, photos of the context etc.), which were taken up by both the artistic avant-gardes of the early 1900s, in particular the Dada movement, and the architect Mies van der Rohe (fig. 2). Graphic representations of this type consist of images with a high level of abstraction, representing a language of rupture capable of carrying forward projects of great imaginative value, highly appreciated by designers but difficult to understand by a non-specialist public. They are based on the use of a very effective language to explain design details. A second type of rendering is the visionary rendering (fig. 3), which takes its inspiration from animation and science fiction films. Its images are very expressive and spectacular, often produced as part of participation in architectural competitions, and maintain continuity with other methods of representation [Nobuyuki 20 17]. They are characterised by a certain degree of abstraction, as they are aimed not at describing projects but at narrating them and evoking an impressive atmosphere [Böhme 20 I0].

A third type of rendering is monomaterial, untextured rendering, whose non-photorealistic (NPR) images have a strongly communicative and expressive purpose. Research is showing that NPR images offer advantages when architecture needs to interface with other domains. For example, the use of these renderings in the medical field allows doctors to visualise an operating room with an NPR image, making easier the complex reading of the data it contains (fig. 4). 
This is a language used only during the work phases, and never for the final communication to the public, in analogy with the sketches made during the design concept stages.

A fourth type of rendering is the schematic one, which integrates the representative techniques typical of axonometry and Veduta paint (Vedutismo), with bird's eye views, where the volumes of the buildings are represented as geometric solids, while what surrounds them (nature, people, skies etc.) is very detailed [De Seta 1999] (fig. 5).

The last type of rendering is photorealistic, where the representation increasingly appears like a photograph. It is undoubtedly the most widespread type of representation, but it has the limitation of favouring certain aspects of the project and minimising others, thus having a decisive influence on reality. The language of photorealism can be declined in various ways: on one side there are visionary renderings, characterised by a certain degree of abstraction that evoke the atmosphere rather than the actual project; on the other side there are promotional renderings, through stereotyped images created by lowering the point of view and

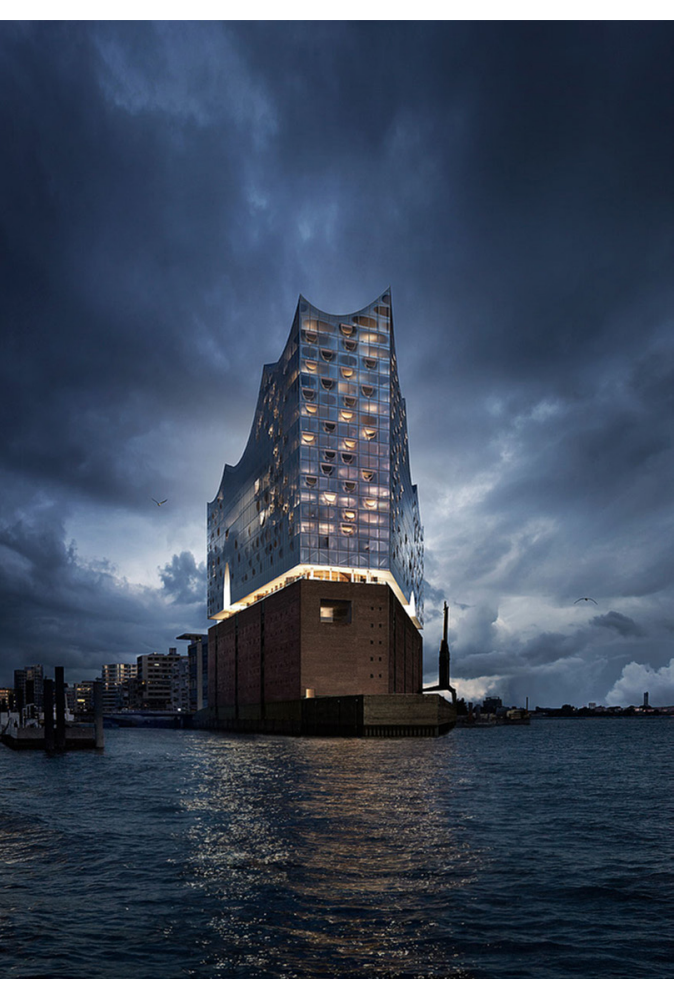

using wide angles to make interior spaces appear larger, neutralising external disturbing elements in order to convey the message of cleanliness, serenity and well-being [Vesely 2004]. In addition to these types, there are also renderings that go beyond realism to the point of becoming hyper-realistic, synthesising a large amount of information into a limited series of highly detailed images. In order to obtain these images, the designed work is never shown as separate objects: the aim is to render the transience of the phenomena that characterise reality [Lever, Richardson 1984]. Attention is paid to the passing of the hours of the day, the changing seasons and weather conditions, as well as the presence of people and objects that animate the scene. The elements in the 3D scene are so detailed that they reproduce the same behaviour they would have in nature, giving back emotions and tactile sensations to the observer.

In the latter two cases, from the point of view of representation, we can find elements with a common denominator: the presence of specific weather and light conditions (fog, snow, mist, cloudy skies, etc.), the mobility of the point of view to emphasise the plasticity of the design -which is the only thing that is not realistic, as no one will ever be able to appreciate 
Fig. 4. Example of rendering with NPR image.

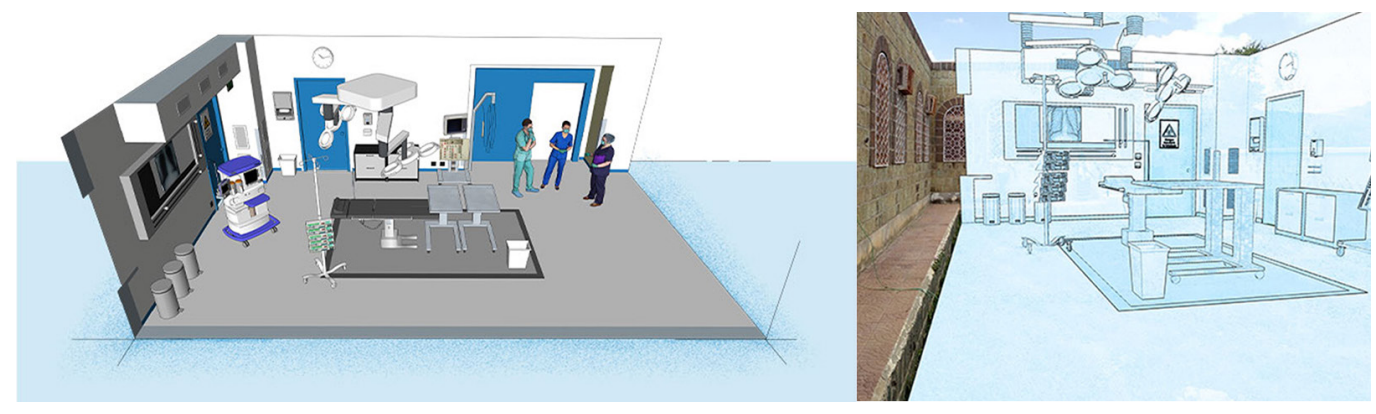

the building from that perspective- and the use of transparency effects. If the first factor refers to Romantic painting, the second refers to 1700 s Veduta painting (for example by Canaletto, Bellotto, Gaspar Van Wittel) and the third finds a suggestion in the iconography of the modern movement, as in the works of Julius Schulman (fig. 6).

A category of renderings that makes extensive use of transparency is the one which uses the flying camera technique, i. e. a close-up view of a building, usually tall and transparent, in which the interior spaces are visible and inhabited [Rowe, Slutzky 1965, pp. 45-54]. This variant takes its inspiration from Michael Wolf's images (fig. 7).

It is important to emphasise that the order of the elements that compose a scene can totally change the narrative [Wolf 2008]. Working with the arrangement of furniture finds references in Zimmerbild paintings (representation of a room) [Gere 1989]. This type of painting originated in England at the end of the seventeenth century with only a descriptive purpose and spread throughout Europe towards the middle of the eighteenth century as a real painting. It can be considered as the first figurative drawing of interior architecture. The absence of the human figure is what characterises the Zimmerbild (fig. 8).

The first architects who used this type of image were the Scottish brothers Robert and James Adam, during the second half of the 1700s. What made Adam's drawings unique was the realism of the image and a skilful and conscious use of perspective where details, proportions, light and shadow were perfectly prefigured (fig. 9). The use of perspective,

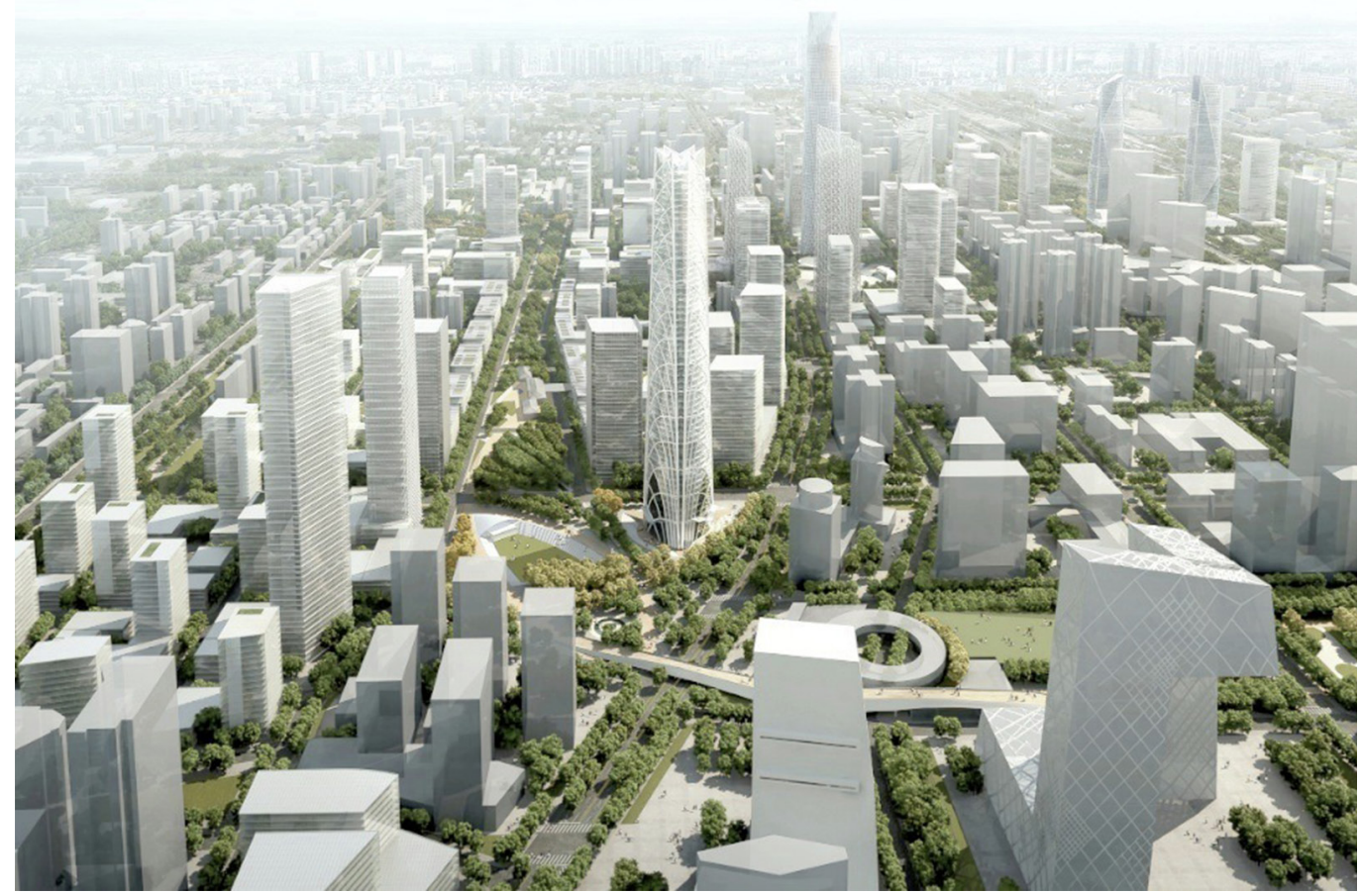


Fig. 6. On the left, works by Canaletto, Bellotto

GasparVan Wittel; on

the right a wor Schulman.

Fig. 7. Examples of flying camera renderings: image works by Michael Wolf.
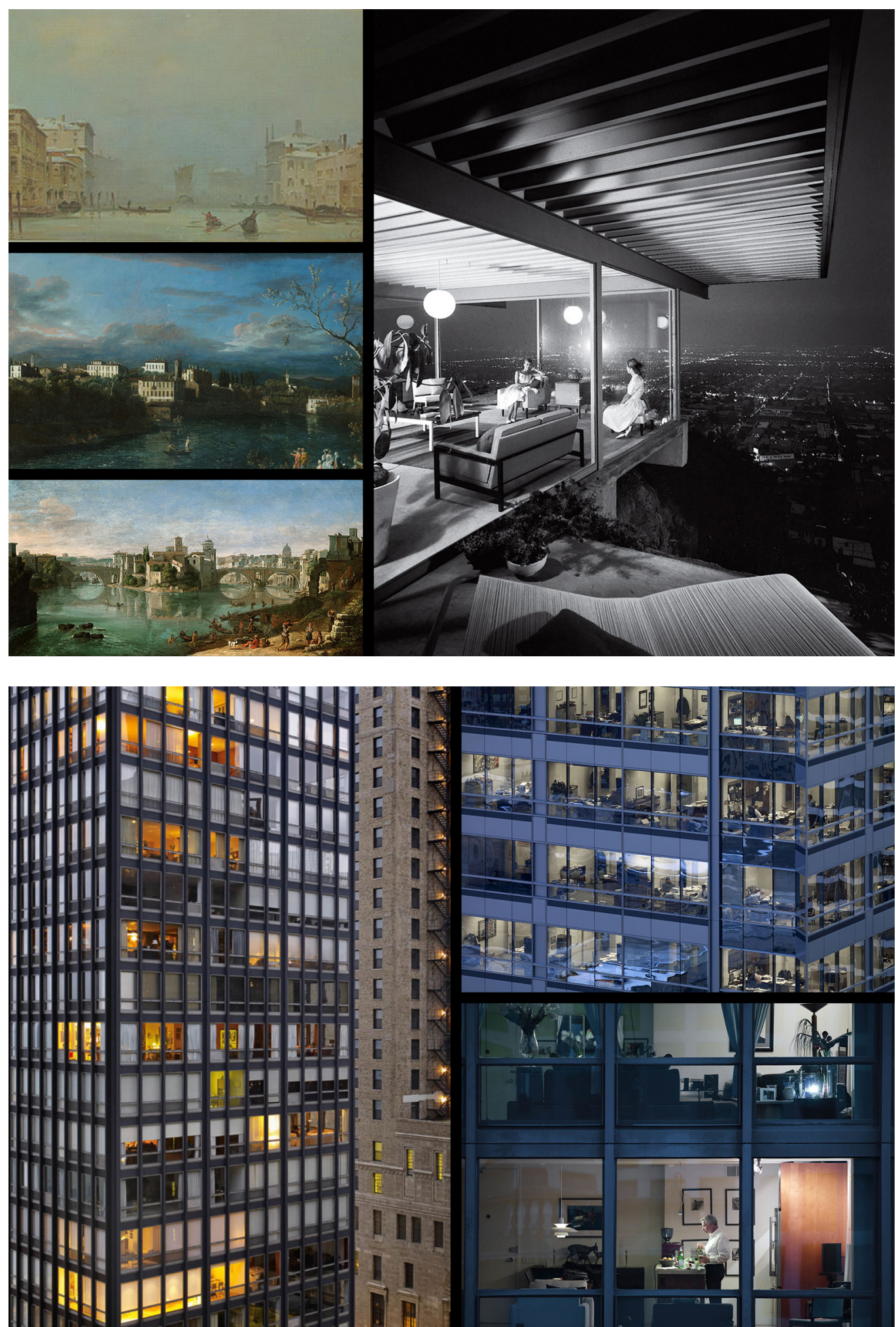
the respect of proportions, the precision of textures and materials, the accuracy of details, lights and shadows are able to faithfully render the space: today, all this is enclosed in rendering representations [Bolton 1984]. The potentials linked to the use of perspective in the figuration of domestic interiors can also be found in Charles Rennie Mackintosh, whose drawings of Speise Zimmer and Musik Zimmer (fig. 10) reveal a great spatial control and a contemporary character [Howarth 1952]. In particular, his representations are characterised by the use of the vertical element repeated in series (high-backed chairs, dangling chandelier cables, flowers with tall stems), by a skillful construction of perspective, with an asymmetrical vanishing point, and by dark or pale colours. These are further elements that underlie a rendering.

The language of photorealistic renderings therefore has common characteristics, such as: the dematerialisation of the physical elements, through the use of transparencies and colours independent from those of the materials; the simulation of surface effects (shading and texturing); the effects of light, not only through shadows but also through reflection and diffusion effects of light radiation; the presence of dark backgrounds; the absence of clear contours and intersections, visible only through a change of colour; the use of effects such as the deformation of the perspective plane; the adoption of multiple points of view to simulate the time factor; depth of field; the artificial perturbation of surface (bump-mapping) and shape to produce irregular geometries (displacement-mapping); the use of the accumulation of reflected or refracted projected light; the simulation of the blurring of fast-moving objects (motion blur).

Therefore, the evolution with respect to Mies van der Rohe, to the Zimmerbilds, and to the Veduta painters does not consist in the method of representation, which is always based on the adoption of perspective, but in its use: perspective becomes continuously changing, and the position of the observer shifts, generating infinite different views of the represented object, through the use of the different digital tools -described above- which if applied incorrectly can generate errors in the views. For example, we can think of unnatural images resulting from the wrong choice in the rendering of the nature of lighting (outdoor/ indoor and natural/artificial), in the rendering of the interaction of light with the textures of objects, or in the rendering of the different natural phenomena and events that influence the process of visualisation of the perceived light. An inadequate lighting model generates inadequate architectural visualisations.

Fig. 8. Zimmerbild works characterised by the absence of the human figure.

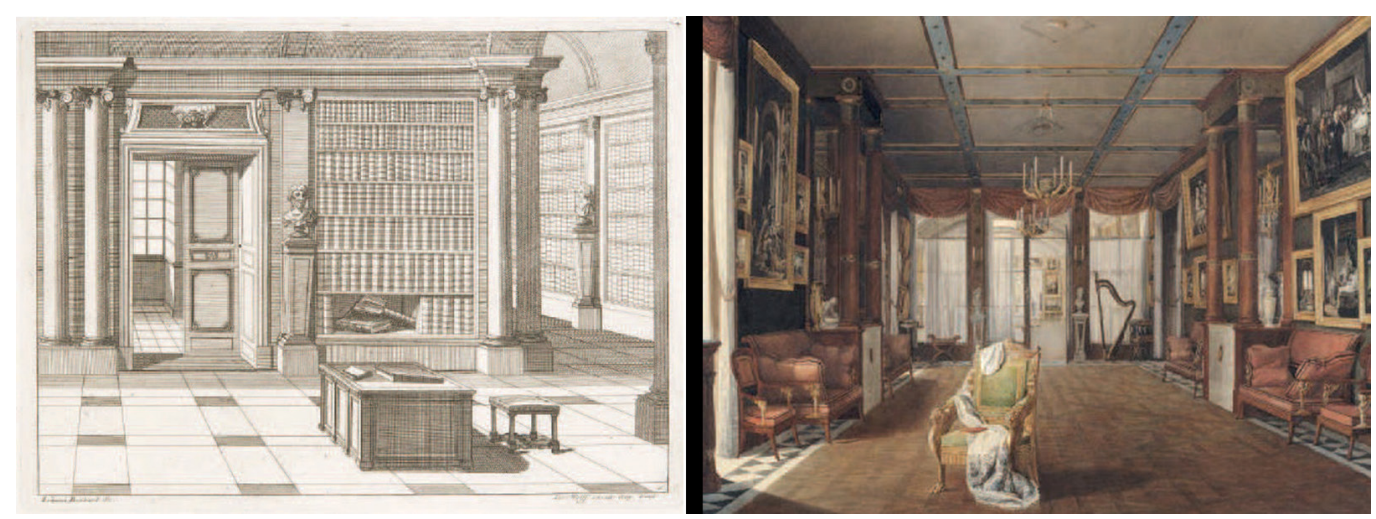

\section{Conclusions}

The communicative capacity of rendering images in architecture - which not only interests designers, but also investors, real estate developers and all users involved in political and economic processes- is expressed through a representation that is always suspended in a difficult balance between the suggestive and descriptive capacity of a design project. This equilibrium is very often unbalanced in favour of aspects more related to the narrative and 
Fig. 9. Work of the brothers Robert and James Adam.

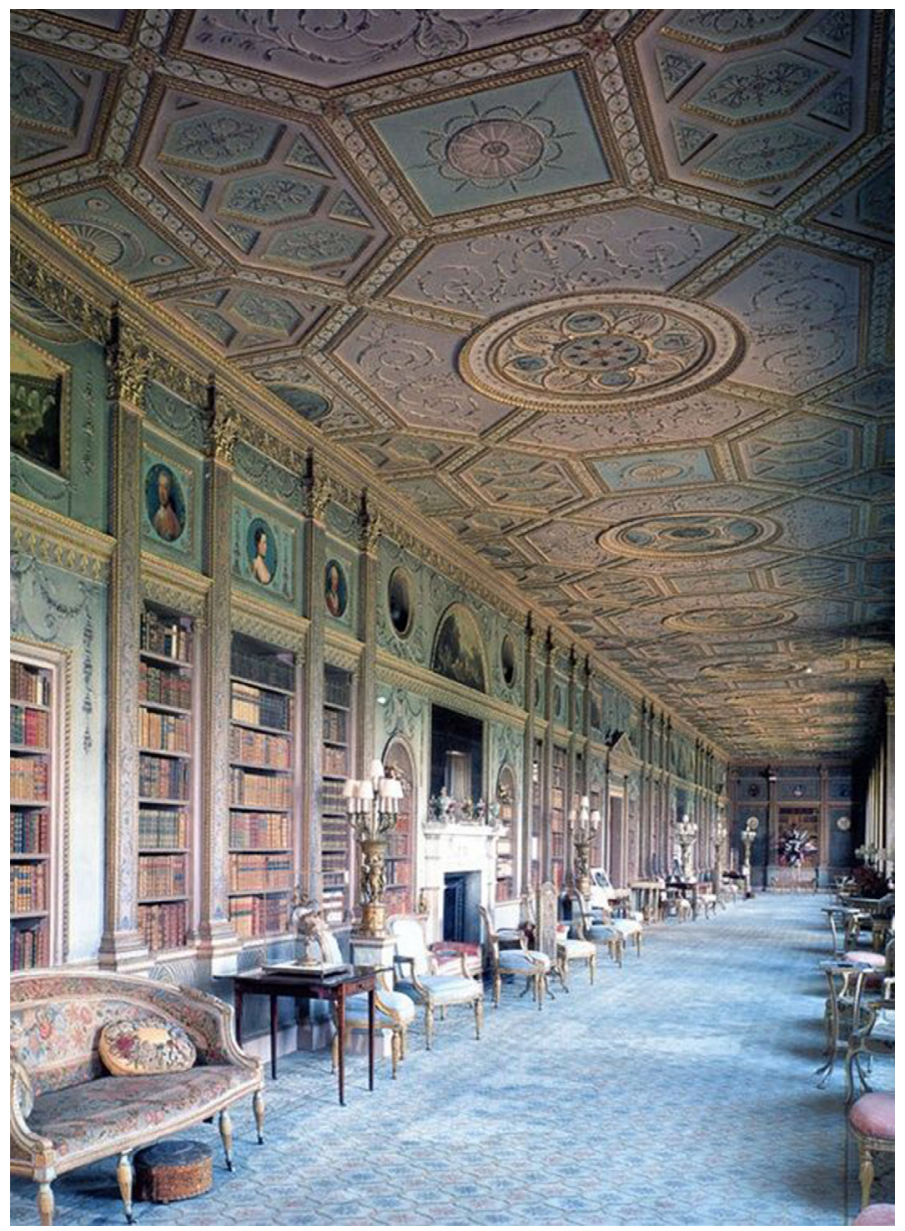

emotional sphere. The spectacular nature of the renderings captures the attention on the most successful aspects of the project, minimising the negative and critical ones in technical terms. In addition, renderings tend to create a global geography of places where the landscape in which the project is inserted is dissolved in a sort of abstract and globalised geography, detached from its context, but with a clear power in terms of communication, media and social issues. The inclusion or exclusion of certain elements (e. g. a certain type of people, furniture, etc.) from the images has undoubtedly an enormous power of orientation and social involvement, and this is exactly what constitutes the great potential of representation. Indeed, rendering is today the main language for communicating and presenting new architecture, contributing to a narrative on a global scale.
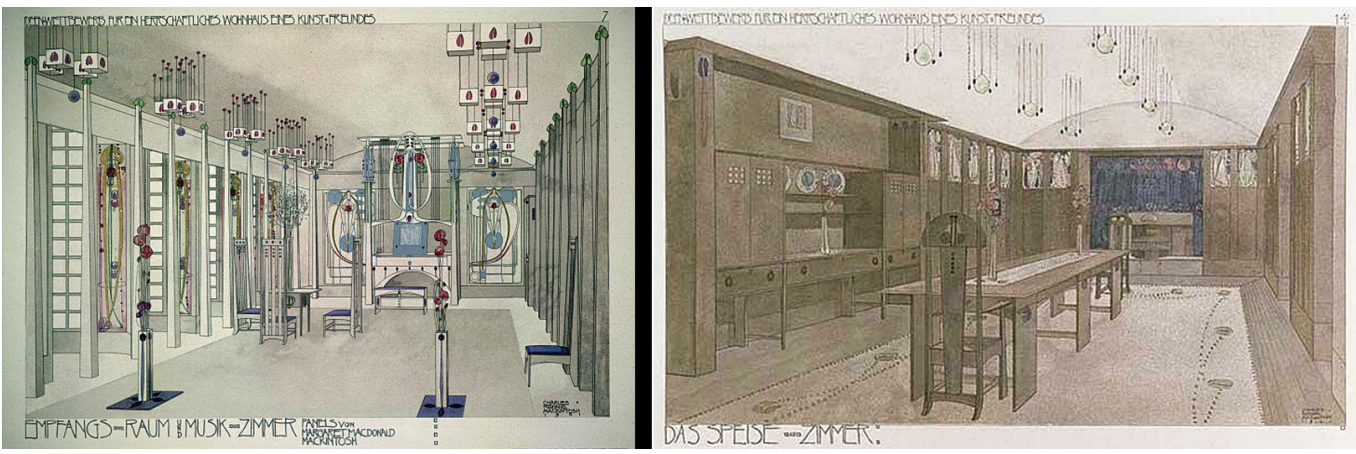

Fig. 10. Works by Charles Rennie Mackintosh: on the left the Musik Zimmer and on the right the speise Zimmer. 


\section{References}

Agostini N. (1983). I luoghi di Raffaello a Roma. Roma: Multigrafica Editrice.

Carloni L. (2008). Vincenzo Pagani. Un pittore devoto tra Crivelli e Raffaello. In V. Sgarbi (a cura di). Vincenzo Pagani. Un pittore devoto tra Crivelli e Raffaello. Catalogo della mostra (Fermo, Palazzo dei Priori, 3 I maggio-9 novembre 2008). Cinisello Balsamo: Silvana editoriale, pp. 72-74, cat. 28

Carpo M. (2017). The second digital turn. Design beyond intelligence. Cambridge, London: MIT Press.

Cellini P. (1960). Nota tecnica sul restauro. In Bollettino d'arte, 45, pp. 92-96.

Cheng R., He C., Jin Y., Yao X. (2018). Model-based evolutionary algorithms: a short survey. In Complex \& Intelligent Systems, $\mathrm{n}$ 4, pp. 283-292. <https://doi.org/I0.1007/s40747-018-0080-I> (accessed on 2021, February 20).

Eslami D., Di Angelo L., Di Stefano P., Pane C. (2020). Review of computer-based methods for archaeological ceramic sherds reconstruction. In Virtual Archaeology Review, n. I I (23), pp. 34-49. <https://doi.org/I0.4995/var.2020.I3134> (accessed on 2021, February 20).

Giacomini F. (20|4). L'incanto dell'Affresco: capolavori strappati da Pompei a Giotto da Correggio a Tiepolo. In L. Ciancabilla C. Spadoni (a cura di). L'incanto dell'Affresco: capolavori strappati. Catalogo della mostra (Ravenna, Loggetta Lombardesca, 16 febbraio- I 5 giugno 20 I4), vol. I. Cinisello Balsamo. Silvana editoriale, pp. 78-79, cat. 3.

Ginzburg S. (2020). L'Isaia di Raffaello nel I5I3. In Arte Cristiana, vol. CVIII, fasc. 917, pp. 90-99.

Mitchell W. J. (1990). The logic of architecture. Design, computation and cognition. Cambridge, London: MIT Press.

Rutten D. (4 marzo 20II). Evolutionary principles applied to problem solving: <https://ieatbugsforbreakfast.wordpress. com/20 I I/03/04/epatps0 I/> (accessed on 202I, February I I).

Salerno L. (1960). II Profeta Isaia di Raffaello e il Putto della Accademia di S. Luca. In Bollettino d'arte, 45, pp. 8I-92.

Slowik A., Kwasnicka H. (2020). Evolutionary algorithms and their applications to engineering problems. Neural Computing \& Application, n. 32, pp. I 2363-12379. <https://doi.org/1 0.1007/s0052 I-020-04832-8> (accessed on 2021, February 20).

Ventra S. (2017). «Le plus beau dessin et la plus belle couleur réunis»: il fascino del Putto reggifestone di Raffaello nell'Ottocento. In Accademia Nazionale di San Luca, Annali delle Arti e degli Archivi. Pittura, Scultura, Architettura, 3, pp. 194-200.

\section{Authors}

Cristiana Bartolomei, Alma Mater Studiorum University of Bologna, cristiana.bartolomei@unibo.it

Cecilia Mazzoli,Alma Mater Studiorum University of Bologna, cecilia.mazzoli2@unibo.it

Caterina Morganti, Alma Mater Studiorum University of Bologna, caterina.morganti4@unibo.it

To cite this chapter. Bartolomei Cristiana, Mazzoli Cecilia, Morganti Caterina (2021). The language of rendering in architectural visualisations. In In Arena A., Arena M., Mediati D., Raffa P. (a cura di). Connettere. Un disegno per annodare e tessere. Linguaggi Distanze Tecnologie. Atti del $42^{\circ}$ Conveg no Internazionale dei Docenti delle Discipline della Rappresentazione/Connecting. Drawing for weaving relationship. Languages Distances Technologies. Proceedings of the $42^{\text {th }}$ International Conference of Representation Disciplines Teachers. Milano: FrancoAngeli, pp. 215-224. 